\title{
A RETÓRICA COMO FERRAMENTA DE LEITURA
}

Dr. ${ }^{\text {a }}$ Iara Bemquerer Costa Professora do Departamento de Linguística, Letras Clássicas e Vernáculas da UFPR.

\section{RESUMO:}

Discute-se neste artigo a utilização de conceitos formulados na Nova Retórica como instrumento de leitura de textos persuasivos de natureza diversa. Após algumas informações sobre o surgimento, expansão e declínio da Retórica Clássica, procura-se enfatizar a revitalização desta área em meados do século XX. Os conceitos nucleares da Nova Retórica são apresentados como instrumentos que orientam a leitura, tomando-se como exemplos artigos de opinião e textos publicitários. São enfatizados os conceitos de tese, auditório, acordo e tipos de argumentos. Finalmente, são apresentados os conceitos de ethos e pathos, incorporados pela Análise do Discurso.

\section{PALAVRAS-CHAVE:}

Argumentação - Nova Retórica - Leitura

\section{ABSTRACT:}

This paper discusses the use of concepts formulated by New Rhetoric as an instrument for reading persuasion articles of diverse nature. Following some information on the appearance, expansion and decline of Classic Rhetoric, the renewal of this field in mid 20th Century is emphasized. The core concepts of New Rhetoric are presented as guides for reading, from examples of opinion articles and advertising. The concepts of thesis, auditorium, accord and types of arguments are emphasized. Finally, the concepts of ethos and pathos are presented, incorporated into Discourse Analysis.

\section{KEYWORDS:}

Argumentation - New Rhetoric - Reading

\section{A Retórica Clássica e sua revitalização na Nova Retórica}

A retórica surgiu na Sicília grega entre os anos 480 a.C. e 399 a.C., depois que os tiranos, ou seja, os dominadores foram expulsos e se constituiu um novo estado, organizado a partir de princípios democráticos. Com o fim do regime autoritário, os cidadãos reclamavam seus bens, dos quais haviam sido despojados pelos antigos mandatários. Apresentavam essas reclamações a um juiz e diante de um público ouvinte. Essa prática deu origem a um conjunto de técnicas desenvolvidas para a organização argumentativa dos discursos. Foi o surgimento da retórica.

Nesse contexto, a retórica nasceu em virtude de uma necessidade prática e foi difundida primeiramente como retórica judiciária. Os gregos sicilianos não tinham advogados, por isso os litigantes tinham que redigir suas queixas e lê-las perante os tribunos. Como ficou evidente que as causas dos discursos melhor 
redigidos eram mais bem-sucedidas, surgiu uma classe de logógrafos profissionais que ouviam e redigiam as queixas dos cidadãos. Seriam os primeiros advogados. Ao mesmo tempo, surgiram retores, logógrafos ou não, que ensinavam técnicas que se baseavam nas maneiras de comprovar o verossímil. Seriam os primeiros professores de retórica. Centro da cultura na época, Atenas incorporou a técnica retórica dos habitantes sicilianos aos seus processos jurídicos.

Os antigos retores sistematizaram a elaboração do discurso, apontando quatro partes (etapas) em sua elaboração: invenção (heurésis - escolha dos argumentos); disposição (taxis - ordem em que os argumentos aparecem no discurso); elocução (lexis - estilo em que um discurso é apresentado - fase em que o discurso é escrito e que inclui as figuras de estilo); ação (hypocrisis proferição do discurso, com ênfase nos gestos usados na apresentação diante do público).

Na história da Retórica Clássica, é importante destacar a contribuição de Górgias, cujos discursos impressionavam pela exploração de figuras de linguagem, o que levou ao reconhecimento do estatuto literário da prosa retórica. A retórica se constitui como uma arte e orienta a produção de discursos que obtêm a adesão do auditório não apenas pela convicção racional diante de um discurso com articulação lógica, mas também pela persuasão que implica num engajamento emocional da parte do seu público ouvinte. Ou seja, o uso eficiente da retórica deveria conquistar o auditório tanto nos corações quanto nas mentes.

Entre as obras de Aristóteles (384-322 a.C.) encontra-se o livro que hoje se conhece pelo nome de Retórica. A marca inovadora desse filósofo foi imprimir ao estudo da retórica duas características: a observação e o espírito de sistema. A retórica é, para Aristóteles, uma ferramenta que pode ser útil no mundo jurídico, na prosa literária, na filosofia e no ensino, mas que, em si mesma, é indiferente: pode servir tanto ao bem quanto ao mal. O filósofo dá grande importância ao ensino da retórica. O domínio das técnicas argumentativas proporciona ao cidadão que se sinta lesado ou agredido, ou que deseje expor suas idéias sobre qualquer assunto, um método que lhe permite argumentar em defesa de seu ponto de vista na presença de qualquer público. Segundo pensamento aristotélico, a retórica é um instrumento imprescindível para a formação do homem universal.

Na cultura clássica a retórica gozou de grande prestígio entre os gregos e romanos: era considerada fundamental na formação do cidadão. Mesmo depois da queda do Império Romano do Ocidente, ela continuou a ser cultivada dentro da Igreja, como um método importante para a produção de textos para conquistar e conservar a adesão dos fiéis aos princípios religiosos. A tradição de escrita dos sermões, por exemplo, sempre se beneficiou da contribuição da retórica. 
É só com o humanismo do século XVI que começa, de fato, o declínio da retórica. A partir dos séculos XVII e XVIII, a retórica foi, ao que parece, excluída das ciências naturais, da matemática e da filosofia. O treinamento em retórica continuou ainda servindo, até o século XIX, aos debates jurídicos, à política e à pregação. Na maior parte dos contextos, contudo, prevaleceu durante séculos a avaliação pejorativa da retórica, considerada como a arte de enganar, como recurso que permite a elaboração de discursos que impressionam pela forma, sem ter um conteúdo consistente.

Na metade do século XX, observa-se uma revitalização dos estudos retóricos, sobretudo a partir dos trabalhos de Chaïm Perelman, em uma abordagem chamada por esse autor de Nova Retórica. Esses estudos são marcados por algumas diferenças em relação à Retórica Clássica. Seu objetivo principal não é mais a formação do cidadão para produzir discursos, mas está centrado na interpretação das formas modernas dos discursos persuasivos: o discurso político, a linguagem da propaganda, as produções não-verbais, entre outros.

No final do século $\mathrm{XX}$, especialmente na última década, observa-se uma nova retomada das contribuições da retórica, agora pela Análise do Discurso francesa, que incorpora os conceitos de ethos (a imagem de si mesmo projetada discursivamente pelo autor) e pathos (a imagem do interlocutor que o autor leva em conta na produção do discurso) (Maingueneau 2005, 2006, 2008).

Nesse contexto, nos questionamos sobre a utilidade da retórica para o profissional de letras neste início do século XXI. Em resposta, procuraremos mostrar seu papel como um instrumento auxiliar para uma interpretação nãoingênua de discursos diversos: políticos, publicitários, jornalísticos. Para isso, procuraremos destacar os conceitos que constituem os pilares da Nova Retórica e, ao mesmo tempo, usá-los como auxiliares na interpretação de textos.

\section{Conceitos nucleares da Nova Retórica}

Perelman e Olbrechts-Tyteca (1996) discutem algumas questões anteriores à formulação de uma teoria da argumentação. Um primeiro ponto destacado por eles é a necessidade de levar em conta que a adesão do interlocutor a uma tese pode ter intensidade variável: diante dos argumentos apresentados por alguém, podemos concordar totalmente e assumir a defesa do mesmo ponto de vista, mas podemos também concordar parcialmente com a opinião que essa pessoa nos apresenta. Daí a necessidade de estabelecer uma distinção entre os raciocínios e procedimentos discursivos relativos à argumentação e aqueles que se referem à demonstração e à dedução. Esses últimos procuram chegar a evidências absolutas, através da apresentação das provas que devem demonstrar determinadas proposições de forma definitiva, de tal modo que qualquer pessoa razoavelmente inteligente tenha de aceitar a demonstração. Já a argumentação pode levar a graus variáveis de aceitação de um ponto de vista. 
Perelman e Olbrechts-Tyteca (1996, p. 4) ressaltam a importância de uma teoria da argumentação como um instrumento para a produção e leitura de textos. Para esses autores, "o objeto dessa teoria é o estudo das técnicas discursivas que permitem provocar ou aumentar a adesão dos espíritos às teses que se lhe apresentam ao assentimento" (grifos no original). Essa definição já faz uso de um conceito central na teoria da argumentação: a tese. Portanto, o primeiro ponto para o estudo da argumentação em qualquer discurso é a identificação da tese defendida pelo autor. Na perspectiva da produção de textos, é fundamental que o autor tenha clareza em relação à tese que quer defender.

Não é qualquer tema que se presta à formulação de teses e ao uso da argumentação. Uma afirmação como "a terra é redonda" já foi objeto de polêmica no passado, mas hoje é uma verdade reconhecida, sobre a qual não há necessidade de se tomar posição. Se alguém fizesse uma pergunta como "você acha que a terra é redonda?" seria ridicularizado ou tomado como louco. Diante de uma demonstração, não cabem questionamentos. Basta um pouco de racionalidade para admitir afirmações como "dois mais dois são quatro", "a água ferve a 100 graus centígrados...", "o surgimento do homem resulta da evolução do macaco". Já os temas que se prestam à elaboração de discursos argumentativos devem ser polêmicos. A argumentação envolve temas sobre os quais haja uma disputa de posições antagônicas. Toda tese se opõe a outras teses concorrentes sobre o mesmo tema. Só faz sentido disputar a adesão de alguém quando essa pessoa pode assumir uma posição diferente daquela com a qual nos identificamos.

É simples elaborar uma lista de temas polêmicos que levam à polarização de opiniões no Brasil atualmente: flexibilização das leis ambientais, ação de movimentos sociais como o MST, redução da maioridade penal, implantação da pena de morte, legalização do aborto, adoção da eutanásia, etc. Cada vez que esses temas são discutidos, há grupos que assumem uma posição favorável e outros que se declaram contrários.

Se um professor de matemática demonstra aos alunos que $3 \times 3=9$, todos os que entenderem a demonstração ficarão integralmente convencidos da correção desse cálculo. Mas se o mesmo professor disser que é favorável à redução da maioridade penal e apresentar um conjunto de razões para fundamentar seu ponto de vista, ele certamente não conseguirá convencer todos os alunos. Alguns vão concordar, outros discordar e alguns vão concordar parcialmente, e considerar a tese aceitável sob certas condições. Essa diversidade de posições que as teses polêmicas suscitam pode ser observada, por exemplo, na seção Tendências/Debates do jornal Folha de S. Paulo. O jornal propõe temas polêmicos a especialistas em várias áreas e divide os artigos em três grupos: sim (concorda com a tese), $n$ ão (discorda), em termos (concorda parcialmente, sob certas condições). 
Para apresentar os conceitos usados pela Nova Retórica para a análise de textos, vamos começar com um exemplo. Trata-se de um artigo de opinião publicado no jornal Folha de S. Paulo e que servirá de referência para a discussão dos conceitos de tese, auditório, acordo e para a identificação de alguns tipos de argumentos.

\section{Um país perverso}

Jânio de Freitas

\section{A vastidão da miséria negra e branca é o curso normal de uma história a que os indígenas não poderiam escapar}

Na excitação criativa do governo Juscelino, cujas inovações de sentido social, ou simplesmente humanitárias, estiveram longe do nível de prioridades, uma delas foi extraordinária pela originalidade e no objetivo. Eram as Unidades Sanitárias Aéreas, que estariam fazendo 50 anos, se sobrevivessem ao golpe de 64. Idéia da figura especialíssima de Noel Nutels, sanitarista brasileiro com origem na Ucrânia, as Unidades consistiam em uma equipe formada por um clínico, dentista, oftalmologista e outras especialidades, equipamentos portáteis de exames e alguns remédios, tudo levado em um velho avião da FAB para sucessivas aldeias indígenas.

Cada tribo visitada era toda ela submetida, quase sempre com a colaboração diplomática de um dos Villas Bôas ou outro dos grandes sertanistas da época, aos vários exames ali possíveis, para um registro sanitário das suas condições e eventuais providências. Nas tribos de contato mais recente com os brancos - eram o alvo principal - os exames levaram a constatações nem de longe esperadas: a saúde era uma combinação de perfeições humanas muito mais completa e difundida do que se podia imaginar.

Os xavantes, homens e mulheres maciços e altos, sempre sorridentes mas ressabiados, como confirmação da sua fama de irascíveis, deram a chave para minha reportagem em "Manchete": entre eles, não foi encontrada nem ao menos uma cárie, nem uma só para constar nos registros algum achado. (Por coincidência, a edição dessa reportagem iniciou a prática de um conceito novo de estética e comunicação visual no jornalismo de revista brasileiro, depois passado ao jornalismo diário no "Jornal do Brasil" - origem nunca percebida pelas "pesquisas" sobre a "imprensa em transição").

Tive há pouco notícia daqueles xavantes que faziam e viviam o paraíso da saúde inimaginável: 80 famílias xavantes (as últimas?) vão receber o Bolsa Família, como socorro para tentarem escapar à subnutrição e às doenças que as devastam.

A vastidão de miséria negra e branca que está por toda parte no Brasil, como destino de pelo menos um quarto da população, é o curso normal de uma história - a da "civilização brasileira" - a que os indígenas não poderiam escapar. As florestas caem sob a ferocidade da agroindústria, os morros urbanos são favelas, as periferias das cidades de riqueza são aglomerados da vida desumana. Que país perverso é o Brasil, tal falsamente pacífico, generoso, sentimental até.

(Folha de S. Paulo, 21 nov. 2007)

Diante de um artigo de opinião como esse, publicado em um jornal, o leitor se coloca como destinatário do artigo de Jânio de Freitas. Identifica o ponto de vista do autor, reconhece os argumentos usados para sustentar esse ponto de vista e assume uma posição diante do que leu: concorda, discorda, elogia, critica etc. O uso de alguns conceitos da retórica é uma ferramenta que pode melhorar a qualidade da leitura.

\subsection{A tese}

Tomemos, em primeiro lugar, o conceito de tese. O que é uma tese na 
retórica? É a posição, o ponto de vista do autor diante de um tema polêmico. O ponto de partida para a interpretação de qualquer texto de opinião é a identificação da tese defendida pelo autor, assim como o ponto de partida para a produção de um texto de opinião é ter clareza sobre a tese a ser defendida.

Voltemos ao texto "Um país perverso". A organização argumentativa desse texto tem como núcleo a tese do autor, seu ponto de vista sobre a extensão da pobreza no Brasil. Essa tese aparece na frase destacada antes do texto: "A vastidão da miséria negra e branca é o curso normal de uma história a que os indígenas não poderiam escapar". Aparece depois formulada no último parágrafo e poderia ser parafraseada como: o modelo de desenvolvimento adotado pelo Brasil leva uma parcela significativa de sua população à miséria.

\subsection{0 auditório}

Para escolher os argumentos e organizá-los no texto, o autor /falante leva em conta, em primeiro lugar, os interlocutores, ou, como destacam Perelman e Olbrechts-Tyteca (1996), o "auditório", definido como "o conjunto daqueles que o orador pretende influenciar com sua argumentação (p. 22). Esses autores destacam também que o importante, na argumentação, não é saber o que o próprio orador considera verdadeiro ou probatório, mas qual é o parecer daqueles a quem ele se dirige" (p. 26).

$\mathrm{O}$ autor/falante seleciona seus procedimentos argumentativos a partir de uma representação, uma imagem do seu interlocutor, que pode ser (ou não) construída a partir do conhecimento real do grupo particular de indivíduos que constituem seus leitores/ouvintes reais. Assim, um segundo passo na interpretação do texto de Jânio de Freitas reproduzido acima envolve a resposta à questão: a quem o autor se dirige nesse texto? Quem ele quer convencer com seus argumentos? Qual é seu auditório?

Uma primeira pista para a identificação do auditório é o veículo em que o texto foi divulgado: o jornal Folha de s. Paulo. É um jornal que dá ênfase à informação e à formação de opinião destinada a uma faixa ampla de leitores, em especial a uma classe média concentrada especialmente na região sudeste. É um jornal que se apresenta como crítico e independente, voltado para leitores com interesses diversificados. Quando se estabelece a relação entre o leitor da revista e a tese proposta pelo autor observa-se que não há nenhum apelo a uma tomada de decisão, a nenhuma ação de curto ou médio prazo. O que o jornalista quer é a adesão dos leitores a uma posição crítica em relação ao modelo de desenvolvimento brasileiro, postura que pode ter um reflexo em várias ações realizadas posteriormente pelos leitores. Por exemplo, essa postura crítica pode estar relacionada à escolha de determinados candidatos, comprometidos com políticas sociais que ajudem a reduzir a miséria no país.

Para sensibilizar os leitores e conseguir sua adesão à tese, o autor recorre a um conjunto de valores supostamente compartilhados pelos leitores da 
revista. O conceito de "acordo", incorporado à Nova Retórica, explicita a importância desses valores na construção argumentativa.

\subsection{0 acordo}

Uma característica comum a todas as formas de argumentação é a pressuposição de que os interlocutores (o auditório) compartilhem de um conjunto de afirmações implícitas (premissas), que são admitidas como um "acordo" prévio, sobre o qual toda a argumentação é construída. Fazem parte desse acordo: fatos, verdades, hierarquias, valores. Na maioria das vezes esses elementos, que sustentam a argumentação, não são apresentados explicitamente, mas apenas pressupostos.

O acordo envolve, primeiramente, aquilo que é real: fatos, verdades, presunções. O reconhecimento de que algo exista, ou de que um fato seja verídico pode sustentar o uso argumentativo dessas informações. O acordo envolve também o que Perelman e Olbrechts-Tyteca chamam de "lugares", ou seja, aquilo que é preferível em escalas de valores supostamente compartilhadas pelos interlocutores. Os principais lugares apontados por esses autores são:

- O lugar da quantidade, que subjaz a afirmações como:

(a) Um maior número de bens é preferível a um número menor;

(b) Aquilo que atende a mais finalidades é preferível ao que atende a menos finalidades;

(c) O que é mais duradouro é preferível ao menos duradouro;

(d) O todo é melhor do que a parte.

- O lugar da qualidade, que permite a construção de argumentos centrados na valorização do verdadeiro, do melhor, do que é único, do que é raro, do que é irreparável.

Além desses dois grupos principais, os autores apontam outros lugares tomados como objetos de acordo: a ordem, a existência, a pessoa, a essência, entre outros.

O conceito de acordo é interessante para a leitura de textos persuasivos, pois leva o leitor a identificar os fatos e valores que o autor supõe serem aceitos pelos interlocutores. Há alguns valores que têm um enorme poder persuasivo e que são usados por partidários de posições distintas para a defesa de teses muito diferentes.

A argumentação do texto "Um país perverso" é construída a partir do pressuposto de que os leitores assumam como premissa a valorização da saúde e da qualidade de vida. O acordo em relação a esses valores é tanto qualitativo observe-se a referência às últimas famílias xavantes sobreviventes do contato com a "civilização" - quanto quantitativo - como se vê na indicação de que pelo menos um quarto da população brasileira vive na miséria.

Valores como a justiça, a liberdade, a democracia, a preservação do meio ambiente, o direito à vida têm os mais diversos usos. Basta lembrar a campanha 
contra o desarmamento, por ocasião do plebiscito realizado em outubro de 2005, que associou a manutenção do direito de posse de armas de fogo à liberdade individual. O acordo em relação a valores como respeito ao próximo, civilidade, liberdade pode ser observado também no seguinte texto publicitário, divulgado em 1995, em uma campanha de uma fábrica de cigarros após a proibição do fumo em bares e restaurantes da cidade de S. Paulo, exceto em espaços abertos:

\author{
Não custa nada perguntar ao \\ vizinho de mesa se incomoda \\ acender um cigarro. \\ Não custa nada ao vizinho \\ de mesa reconhecer o direito \\ ao prazer de um cigarro. \\ Não custa nada ser civilizado.
}

A questão não é se você gosta ou não gosta de cigarro.

A questão é se você gosta ou não gosta de liberdade. (Vestibular UFPR - 1996)

Essa campanha publicitária fez um apelo direto ao seu auditório, que é chamado a concordar com a recuperação dos direitos dos fumantes. O público alvo da campanha são os não-fumantes. Esse auditório é interpelado diretamente e chamado a aderir à tese de que a proibição do cigarro em bares e restaurantes deve ser suspensa: Você é civilizado? Você gosta de liberdade? Então reconheça e respeite os direitos dos fumantes.

\title{
2.3 Os tipos de argumentos
}

Perelman e Olbrechts-Tyteca (1996) classificam os argumentos usados nos textos em duas grandes classes: argumentos quase-lógicos e argumentos baseados na estrutura do real. Os argumentos quase-lógicos procuram se aproximar de raciocínios formais, lógicos ou matemáticos. Não se pode dizer que haja simplesmente uma transposição dos raciocínios formais para a argumentação, trata-se apenas de semelhança, de uma forma de apresentação que dá aos argumentos a aparência de uma demonstração.

Estão nesse grupo os argumentos que apelam para relações lógicomatemáticas como a divisão do todo em partes, a comparação, a transitividade, a probabilidade, os cálculos matemáticos. O uso de dados quantitativos na argumentação é muito frequente. É o que se pode observar neste fragmento de uma campanha publicitária do Governo do Rio de Janeiro, divulgada na revista Carta Capital de 27-05-2009:

SOMANDO FORÇAS, ESTAMOS RECUPERANDO O NOSSO ESTADO. VEJA ALGUNS RESULTADOS.

Nos últimos dois anos, o Rio de Janeiro começou a mudar. Já não existem desafios impossíveis. Juntos, podemos fazer mais.

(...)

Educação: o século XXI chega às escolas estaduais.

Cada professor em sala de aula recebeu um laptop com conexão para internet em banda larga, totalizando 50 mil computadores. Todas as 1.600 escolas estaduais 
foram dotadas de laboratórios de informática conectados à internet. Todas as 19 mil salas de aula também receberam um computador com banda larga. No total, a rede estadual possui hoje 10 vezes mais computadores do que tinha 2 anos antes, em 2006.

(...)

O uso dos dados quantitativos e da comparação nesta campanha publicitária limita os argumentos que a oposição poderia usar para questionar a tese defendida pelo governo: de que sua administração é eficiente e apresenta resultados significativos após dois anos de mandato. O questionamento de argumentos que se assemelham a raciocínios lógicos exige muitas vezes um raciocínio semelhante: ou se demonstra que os dados estão incorretos, ou que não se pode extrair deles as consequências pretendidas pelo autor.

Já os argumentos baseados na estrutura do real levam em conta questões práticas: exemplos, ilustrações, fatos reais e especulações sobre suas causas e consequências, relação entre a história ou a posição social de uma pessoa e seus atos, apelo à autoridade, etc. A diferença entre os dois tipos fundamentais de argumentos é explicitada nos seguintes termos:

Enquanto os argumentos quase-lógicos têm pretensão a certa validade em virtude de seu aspecto racional, derivado da relação mais ou menos estreita existente entre eles e certas fórmulas lógicas ou matemáticas, os argumentos fundamentados na estrutura do real valem-se dela para estabelecer uma solidariedade entre juízos admitidos e outros que se procura promover. (PERELMAN; OLBRECHTS-TYTECA, 1996, p. 297)

A maioria dos textos que encontramos na mídia faz uso dos argumentos baseados na estrutura do real. É o que se observa no texto "Um país perverso". A argumentação desse artigo é construída a partir da apresentação de um caso particular. Nos parágrafos iniciais o autor relata um programa de assistência à saúde das tribos indígenas brasileiras na década de 1950, e aponta as excelentes condições de saúde dos xavantes, povo que vivia até então praticamente sem contato com os brancos; no penúltimo parágrafo apresenta dados sobre os mesmos índios em 2007, para mostrar como o contato foi desastroso para essa tribo. O caso particular da miséria dos xavantes a partir da convivência com os brasileiros "civilizados" é comparado à pobreza de um número significativo de brasileiros na periferia das grandes cidades.

Não vamos aqui explorar de forma sistemática os tipos de argumentos estudados pela Nova Retórica, o que nos levaria a ampliar demais esta unidade com a inclusão de vários detalhes adicionais. Preferimos enfatizar apenas as duas grandes classes de argumentos apresentados por Perelman e OlbrechtsTyteca (1996). Esse grau de detalhamento é suficiente para uma indicação de como uma abordagem retórica da argumentação pode ser um instrumento importante na leitura de textos diversos.

\section{O ethos: imagem do autor projetada no discurso}

Os elementos destacados nas seções anteriores - auditório, acordo e tipos 
de argumentos - colocam em evidência o ouvinte/leitor ou a organização do texto. Mas a retórica aponta também a importância da imagem do autor/orador. Não é difícil nos lembrarmos de situações em que ouvimos/lemos um discurso em que alguém defende um ponto de vista e apresenta seus argumentos, mas só obtém como resposta nosso descrédito: "Não acredito em nada do que esse indivíduo diz". Essa imagem do autor pode ter sido construída a partir de informações prévias ou pode estar apoiada na forma como ele se apresenta no momento em que produz seu discurso. A Retórica Clássica usa o termo ethos para se referir à imagem do orador projetada no discurso. Esse conceito é apresentado em uma linguagem mais atual por Fiorin (2008, p.139):

\begin{abstract}
Em termos mais atuais, dir-se-ia que o ethos não se explicita no enunciado, mas na enunciação. Quando um professor diz eu sou muito competente, está explicitando uma imagem sua no enunciado. Isso não serve de prova, não leva à construção do ethos. O caráter de pessoa competente constroi-se na maneira como organiza as aulas, como discorre sobre os temas, etc. À medida que ele vai falando sobre a matéria, vai dizendo sou competente. Como vimos antes, a enunciação não é da ordem do inefável. Por conseguinte, o ethos explicita-se na enunciação enunciada, ou seja, nas marcas da enunciação deixadas no enunciado. Portanto, a análise do ethos do enunciador nada tem do psicologismo que, muitas vezes, pretende infiltrar-se nos estudos discursivos. Trata-se de apreender um sujeito construído pelo discurso e não uma subjetividade que seria a fonte de onde emanaria o enunciado, de um psiquismo responsável pelo discurso. O ethos é uma imagem do autor, não é o autor real; é um autor discursivo, um autor implícito.
\end{abstract}

O conceito de ethos é complementado pelo de pathos, que corresponde à imagem que o orador tem do seu auditório, e que o orienta na seleção dos argumentos. Tão importante quanto esses dois conceitos é o logos, que seria o raciocínio, ou seja, o elemento propriamente dialético e argumentativo da retórica (REBOUL, 2000, p. 36). Segundo Aristóteles, o ethos seria o caráter, a moral que o orador assume ou o que ele parece ser para inspirar confiança no auditório.

O ethos está ligado à pessoa do orador e é construído tanto a partir de suas escolhas discursivas quanto de informações externas. Entre as escolhas discursivas estão o estilo, o gênero discursivo, as afirmações que indicam a vinculação a uma ou outra posição ideológica. Entre as informações exteriores ao discurso estão: o conhecimento prévio sobre o orador e a instituição a partir da qual ele fala, seu modo de se apresentar, de se vestir, seu tom de voz e gestos.

Todos esses elementos contribuem para a construção de uma imagem do orador: honesto, desonesto, simpático, confiável, arrogante, prudente, justo, altruísta, oportunista etc. O sucesso de um discurso argumentativo está vinculado, entre outras coisas, também ao ethos do autor.

\title{
4. Conclusão
}

Nessa rápida apresentação de alguns conceitos nucleares da Nova Retórica, procuramos deixar claro que a visão de que a retórica é a arte do 
discurso vazio e enganador merece ser revista. Somos alvo de discursos persuasivos com uma intensidade nunca vista anteriormente: discursos políticos, religiosos e especialmente publicitários. Em vez de usar a expressão do senso comum para desqualificar esses discursos, dizendo que "é tudo retórica", podemos tomar a técnica de análise dos discursos persuasivos desenvolvida pela retórica para avaliar a forma de construção desses discursos, posicionar-nos diante deles de forma consciente e dispor de instrumentos para refutar as argumentações inconsistentes.

Podemos tomar a retórica como um instrumento para a leitura crítica de textos persuasivos e orientar essa leitura por quatro questões formuladas a partir dos conceitos nucleares formulados por Perelman e Olbrechts-Tyteca:

(a) Qual é a tese, o ponto de vista do autor sobre o tema?

(b) A quem o autor se dirige, quem ele quer convencer com seus argumentos?

(c) Quais são as premissas consideradas consensuais e que se encontram implícitas na argumentação?

(d) Quais são os argumentos usados no texto?

Tal como na Grécia Antiga, ainda hoje a retórica pode ser um instrumento fundamental para a formação das pessoas e para o exercício da cidadania.

\section{Referências}

FIORIN, José Luiz. Em busca do sentido: Estudos discursivos. São Paulo: Contexto, 2008.

MAINGUENEAU, Dominique. Ethos, cenografia, incorporação. In: AMOSSY, R. (org.) Imagens de si no discurso. S. Paulo: Contexto, 2005.

Cenas da enunciação. Curitiba: Criar, 2006.

A propósito do ethos. In: MOTTA, A.R.; SALGADO, L. (org.) Ethos discursivo. S. Paulo: Contexto, 2008.

PERELMAN, Chaïm; OLBRECHTS-TYTECA, Lucie. Tratado da argumentação: A nova retórica. São Paulo: Martins Fontes, 1996.

Retóricas.São Paulo: Martins Editora, 2004.

REBOUL, Olivier. Introdução à retórica. São Paulo: Martins Fontes, 2000. 